\title{
CARACTERIZAÇÃO DE OURO POR ANÁLISE DE IMAGEM AUTOMATIZADA POR FEIXE DE ELÉTRONS
}

\author{
G. P. NERY' ${ }^{1}$, C. ULSEN ${ }^{1}$, H. KAHN ${ }^{1}$, D. ULIANA ${ }^{1}$ e M.M.M.L. TASSINARI ${ }^{1}$ \\ ${ }^{1}$ Laboratório de Caracterização Tecnológica - Universidade de São Paulo, Departamento de Engenharia de Minas \\ e de Petróleo \\ guilherme@lct.poli.usp.br - carina@lct.poli.usp.br - henrique@lct.poli.usp.br - daniel@lct.poli.usp.br -
}

Artigo submetido em novembro/2013 e aceito em dezembro/2013

DOI: http://dx.doi.org/10.15628/holos.2014.1786

\section{RESUMO}

O processamento de metais preciosos é atualmente um dos mais desafiadores da indústria mineral, visto que tem se mostrado economicamente viável a teores cada vez mais baixos e em associações mais complexas. Dessa forma, a identificação das associações de ouro com outros minerais, bem como a determinação da proporção de sua ocorrência em partículas mistas (incluso ou exposto no perímetro das mesmas), é de fundamental importância para a estimativa das recuperações metalúrgicas, definição dos fluxogramas de processamento e ações para aumento da recuperação em operações industriais. No presente trabalho é apresentada uma metodologia de caracterização de minérios auríferos, com baixos teores de ouro, por mineralogia quantitativa por feixe de elétrons com busca automatizada de partículas portadoras de ouro, utilizando o sistema MLA (Mineral Liberation Analyser - FEI). Os objetivos são identificar os grãos de ouro, determinar seu tamanho e forma de ocorrência e as recuperações por cianetação.

PALAVRAS-CHAVE: caracterização tecnológica, ouro, microscopia eletrônica de varredura, análise de imagens.

\section{GOLD CHARACTERIZATION BY AUTOMATED IMAGE ANALYSIS BY ELECTRON BEAM}

\section{ABSTRACT}

The processing of precious metals is currently one of the most challenging in the mining industry, since it has been economically feasible even for lower grades and complex associations. Thereby, the identification of gold associations with other minerals, as well as the proportion of its occurrence in locked particles (enclosed or exposed on particle surface) is fundamental for the estimation of metallurgical recoveries, definition of flow sheets and for supporting modifications in industrial operations to increase recovery. This paper presents a methodology for characterization of low grades ores by SEM-based quantitative mineral analysis for automated search of gold carrier particles, using the software MLA (Mineral Liberation Analyser - FEI). The goals are to identify the gold grains, its size and occurrence and the recoveries in cyanidationctests.

KEYWORDS: process mineralogy, gold, scanning electron microscopy, automated image analysis. 


\section{INTRODUÇÃO}

Atualmente, e em grande parte devido à atual conjuntura internacional, o preço do ouro tem demonstrado um aumento progressivo. Dessa maneira, as jazidas de ouro de menor porte e com minérios de menores teores e maior complexidade de beneficiamento entraram novamente nos planos estratégicos das empresas, possibilitando a implantação de novos empreendimentos e a expansão de outros já existentes. Assim, torna-se fundamental o aprofundamento no conhecimento das características destes minérios e dos seus comportamentos frente aos processos de beneficiamento.

A caracterização tecnológica para fins de beneficiamento se volta à avaliação dos parâmetros básicos do corpo mineralizado, relacionados às alternativas tecnológicas de tratamento de minérios. Assim, envolve o conhecimento de matérias-primas minerais nos aspectos relativos aos seus componentes minerais, desde que o beneficiamento tenha por objetivo a separação de seus constituintes (SANT'AGOSTINO e KAHN, 1997).

Para minérios nos quais o mineral de interesse ocorre como traços, como no caso de ouro, a caracterização difere da abordagem convencional devido ao baixo teor (ppm), o que significa grande dificuldade de se encontrar a fase de interesse para análises qualitativas e quantitativas, uma vez que sua distribuição no minério é heterogênea. Dessa forma, as separações preliminares visando à concentração de minerais em determinadas frações e produtos tornam-se muito mais importantes para concentrar a fase de interesse, uma vez que a própria avaliação desta vai depender de ela ser encontrada (NEUMANN et al., 2002).

Os métodos automatizados de análise por imagem têm demonstrado uma importância crescente no setor mineral devido à confiabilidade dos resultados adquirida nos últimos anos, à complexidade das informações que podem ser avaliadas e à representatividade estatística propiciada pela análise de um grande número de partículas. Aliado a um microscópio eletrônico de alta resolução, sistemas como o Mineral Liberation Analyser (MLA) têm a capacidade de localizar e identificar minerais com partículas em uma faixa granulométrica de $1 \mathrm{~mm}$ até cerca de $1 \mu \mathrm{m}(\mathrm{GU}, 2003)$.

No presente trabalho utilizou-se o MLA, integrado a microscópio eletrônico de varredura (MEV) com fonte de emissão de campo (FEG) aliado a detector de dispersão de energia (EDS) no estudo de duas amostras de minério aurífero com teores da ordem de 0,2 ppm. Os resultados refletem a composição mineralógica da amostra, as associações minerais, a distribuição do tamanho de grãos de ouro, fração em área dos grãos de ouro com perímetro exposto, entre outros.

O ouro exposto pode ser recuperado por processos de flotação ou cianetação, ao passo que o ouro incluso pode ou não ser acessado. Quando o ouro encontra-se incluso em sulfetos, a flotação pode focar na concentração destes para gerar um concentrado rico em sulfetos e ouro; nesse caso, a concentração densitária também pode ser uma alternativa para gerar um concentrado rico em sulfetos. Quando o ouro encontra-se associado a silicatos, a extração destes dependerá de outros métodos de concentração e recuperação, sendo usual a cianetação após a 
adequada cominuição, extraindo-se o ouro tanto exposto quanto o acessível a partir de micro fraturas existente na ganga silicatada.

\section{OBJETIVOS}

O objetivo deste trabalho foi estabelecer um procedimento de caracterização das associações minerais de minérios auríferos de elevada complexidade mineralógica e correlacionar tais propriedades com a recuperação potencial de ouro na lixiviação por cianeto.

\section{MATERIAIS E MÉTODOS}

O estudo foi realizado em duas amostras mineralizadas a ouro e obtido em campanhas de amostragem como apoio ao desenvolvimento de processos de beneficiamento. As alíquotas "tal qual" apresentam teores médios de 0,25 e 0,15 ppm de ouro; tais amostras foram denominadas respectivamente B-020 e S-020.

O procedimento iniciou-se através da etapa de cominuição, abaixo de 0,3 $\mathrm{mm}$ em britador de rolos, seguida de peneiramento a úmido em 0,$21 ; 0,15 ; 0,074 ; 0,037 \mathrm{~mm}$. Com o objetivo de se elevar a estatística de partículas de minerais pesados, incluindo-se o ouro, e também diminuir a quantidade de seções a serem estudadas no MEV-MLA, cada fração granulométrica, excetuando o passante em $0,037 \mathrm{~mm}$, foi concentrada por separação em líquido denso (2,95 $\mathrm{g} / \mathrm{cm} 3$ ) para as observações sistemáticas dos grãos de ouro contidos nos produtos afundados (GOODALL e SCALES, 2007).

Ao final da etapa de separação, os produtos flutuado $(\mathrm{d}<2,95 \mathrm{~g} / \mathrm{cm} 3)$ e afundado $(\mathrm{d}>2,95$ $\mathrm{g} / \mathrm{cm} 3$ ) de cada fração granulométrica foram encaminhados para etapa de lixiviação por cianeto, gerando assim uma solução cianetada e um resíduo sólido, os quais foram objeto de análises químicas para determinação dos teores de ouro.

Alíquotas representativas de cada produto afundado, por fração granulométrica, foram amostradas em amostrador rotativo para confecção de seções polidas para as observações ao MEV-MLA. A caracterização das associações do ouro foi realizada somente no produto afundado a fim de se determinar as formas de ocorrência deste e as associações com outros minerais, sejam silicatos ou sulfetos. No produto flutuado, o ouro ocorre em tamanhos diminutos e associados à ganga silicatada e será recuperado essencialmente por cianetação, sendo as perdas referentes à parcela de ouro não acessível.

Inicialmente, a diferenciação de fases é baseada nos diferentes tons de cinza nas imagens de elétrons retroespalhados (contraste de número atômico) e pela composição química determinada pela microanálise (espectros de raios $\mathrm{X}$ característicos). As análises por MEV foram efetuadas em equipamento Quanta 600FEG (FEI) com espectrômetro de energia dispersiva (EDS) Quantax 400 (Bruker); análises químicas de ouro em amostras foram efetuadas por fire assay.

Um banco de dados das fases minerais identificadas é criado, contendo o espectro de raios $\mathrm{X}$ relativo à composição química de cada fase; a classificação é efetuada por comparação do espectro do banco com o espectro coletado em cada grão durante a busca automatizada. 
Para a busca do ouro e outros minerais de elevado número atômico, é estabelecido como critério a faixa de tons de cinza relativa a estes minerais (contraste BSE) e, em cada imagem coletada, somente partículas portadoras de fases presentes nesta faixa são analisadas por EDS (modo MLA-SPL_Lt). As coordenadas $(X, Y)$ de cada partícula analisada são armazenadas e, após a varredura de toda a seção, cada partícula pode ser observada em detalhe para aferir sua classificação e determinar as associações de ouro e de outros eventuais elementos de interesse presentes ( $\mathrm{Ag}, \mathrm{Te}, \mathrm{Pt}, \mathrm{Pd}$, dentre outros), bem como a composição química das fases identificadas.

A busca automatizada permite a identificação de uma grande quantidade de partículas em espaço de tempo relativamente curto, sendo impraticável ou extremamente moroso de outra forma. As condições operacionais adotadas permitiram detectar a presença de grãos de ouro com dimensões de até $0,5 \mu \mathrm{m}$.

Adicionalmente, ressalta-se que a análise de imagens deve ser precedida por algum outro tipo de análise, física e/ou química, para prover uma compreensão total da composição do minério (GOODALL e SCALES, 2007). No estudo realizado foram efetuadas análises mineralógicas qualitativas por difratometria de raios $\mathrm{X}$, microanálises ao MEV-EDS antes da cominuição das amostras e análises químicas por fluorescência de raios $\mathrm{X}$ sem padrões.

\section{RESULTADOS}

Através da análise de imagens por feixe de elétrons (MEV/MLA) foram determinadas as distribuições do ouro e suas associações, distribuição de tamanho e forma das de grãos de ouro, perímetro exposto e recuperação. A partir das análises químicas nos produtos da cianetação, pode-se correlacionar a recuperação potencial em escala laboratorial com as características microestruturais do ouro observadas no MEV/MLA.

\subsection{Caracterização das associações do ouro}

As imagens resultantes do estudo mostram as diversas fases presentes segundo critério de cores estabelecido. Na Figura 1, observam-se os grãos de ouro (amarelo) de diferentes dimensões e formas de associações.

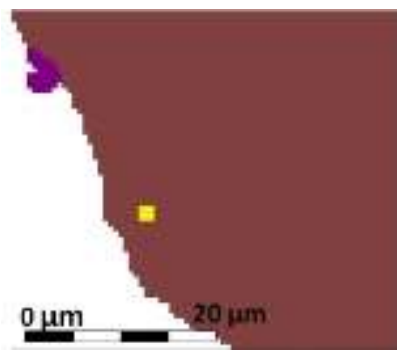

$-0,30+0,21 \mathrm{~mm}$ (grão incluso)

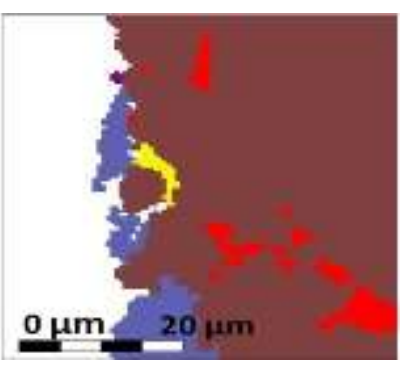

$-0,21+0,15 \mathrm{~mm}$ (grão acessível)

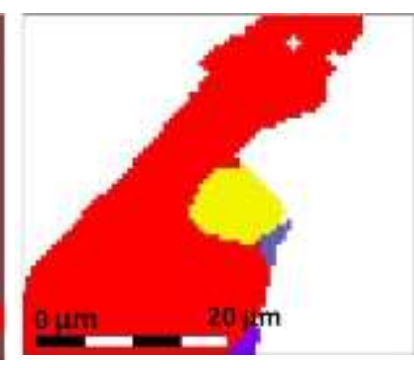

$-0,21+0,15 \mathrm{~mm}$ (grão exposto)

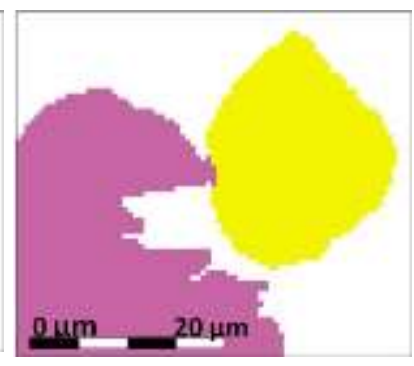

$-0,074+0,037 \mathrm{~mm}$ (grão livre)

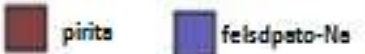
silicato

Figura 1 - Imagens retratando as diferentes formas de associação e tamanho dos grãos de ouro 


\subsection{Associações do ouro}

O sistema foi eficiente na detecção de número significativo de grãos de ouro, identificando 136 grãos de ouro em 110 partículas portadoras na amostra B-020 e 149 grãos de ouro em 129 partículas portadoras na amostra S-020.

Uma vez identificados os grãos de ouro por análise de imagens, é possível determinar a parcela de ouro em contato com outras fases ou exposto no perímetro das partículas (Tabela 1).

Tabela 1 - Sumária das associações minerais do ouro (total $+0,037 \mathrm{~mm}$ ) no produto afundado

\begin{tabular}{c|cccccc}
\hline \multirow{2}{*}{ Amostra } & \multicolumn{6}{|c}{ Associações (\% em perímetro de contato) } \\
& Au exposto & pirita & calcopirita & CuS & silicatos & outros \\
\hline B-020 & 27 & 17 & 26 & 1,7 & 23 & 5,7 \\
S-020 & 20 & 25 & 20 & 24 & 10 & 1,1 \\
\hline
\end{tabular}

CuS - Covelina/calcosita, silicatos - mica, feldspato sódico e outros silicatos, Outros - óxido de ferro e outros

Nas amostras estudadas, vemos então grãos de ouro expostos no perímetro das partículas (Au exposto), associados a sulfetos e também a silicatos. Na amostra S-020, nota-se a presença expressiva de ouro associado à fase CuS (covelina/calcosita), enquanto na amostra B020, as associações com silicatos também são relevantes.

No caso de se optar pela flotação de ouro com sulfetos objetivando a concentração de ouro, devem-se considerar as associações do ouro com pirita, calcopirita; já para a amostra S-020 deve-se também considerar a presença de sulfetos secundários de $\mathrm{Cu}$ (covelina/calcosita).

\subsection{Distribuição do tamanho dos grãos de ouro}

A distribuição de tamanho dos grãos de ouro (\% em massa) obtida, para cada fração granulométrica e o total, é mostrada na Figura 2. As curvas de distribuição acumuladas abaixo dos grãos de ouro não seguem a mesma tendência das curvas granulométricas, ou seja, frações mais grossas podem conter ouro com distribuição mais fina (vide amostra S-020) e vice-versa.
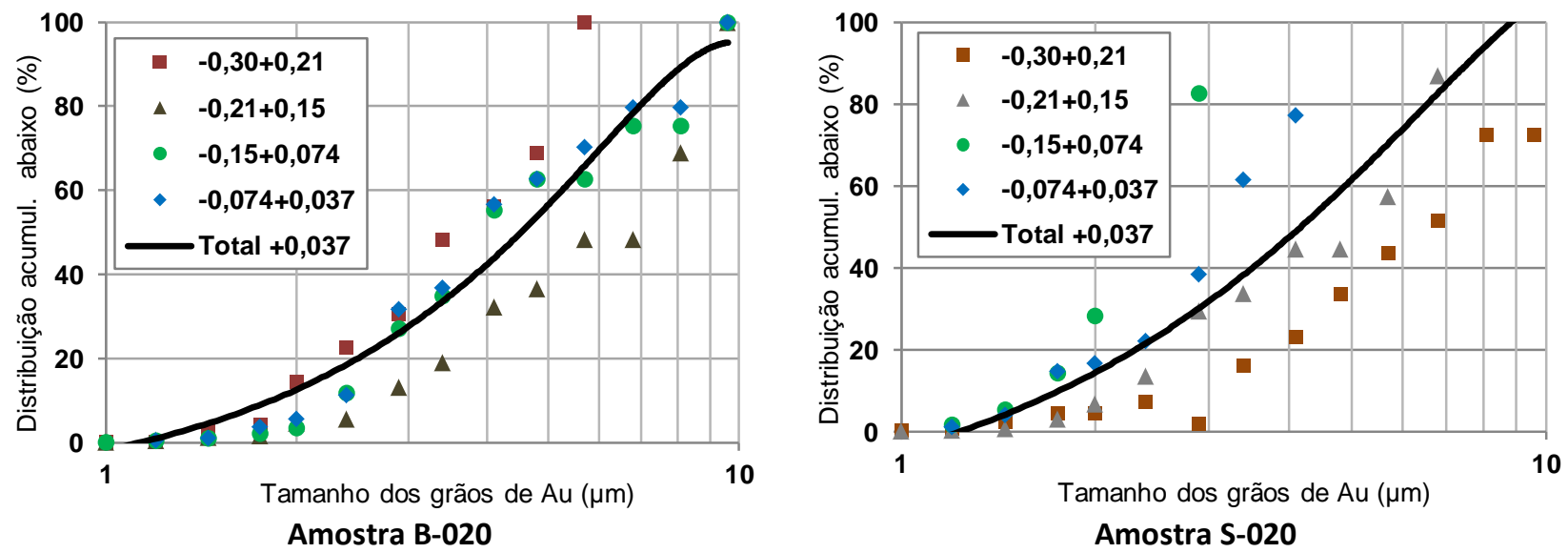

Figura 2 - Distribuição granulométrica dos grãos de ouro (MLA) para as duas amostras 
A forma dos grãos de ouro pode estar relacionada ao mecanismo de formação do depósito e foi também avaliada. A frequência de grãos de ouro (número de grãos) por tamanho (em termos de ECD - diâmetro do círculo equivalente) é apresentada na Figura 3.

Ao todo foram analisados 241 grãos de ouro, cujo tamanho médio em ambas as amostras é da ordem de $3 \mu \mathrm{m}$ (com poucos grãos de ouro acima de $8 \mu \mathrm{m}-1,5 \%$; Figura 3). Quando ponderados pela massa, $50 \%$ dos grãos de ouro encontram-se abaixo de $5 \mu \mathrm{m}$ (Figura 2).

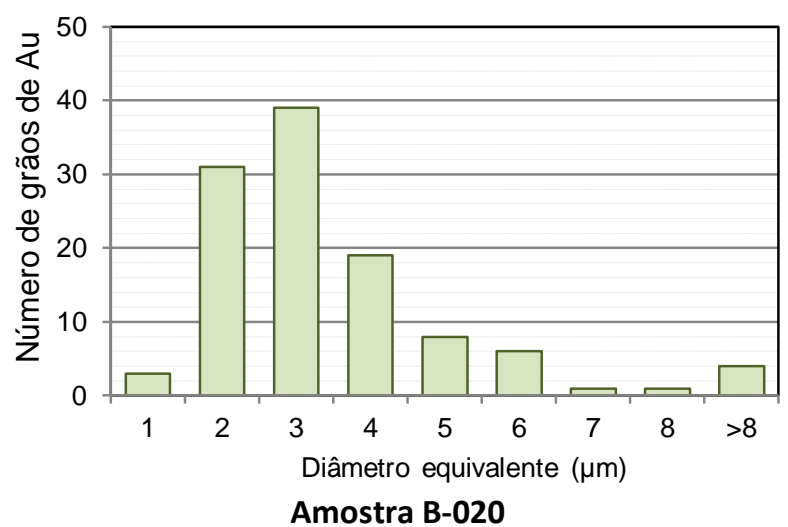

Amostra B-020

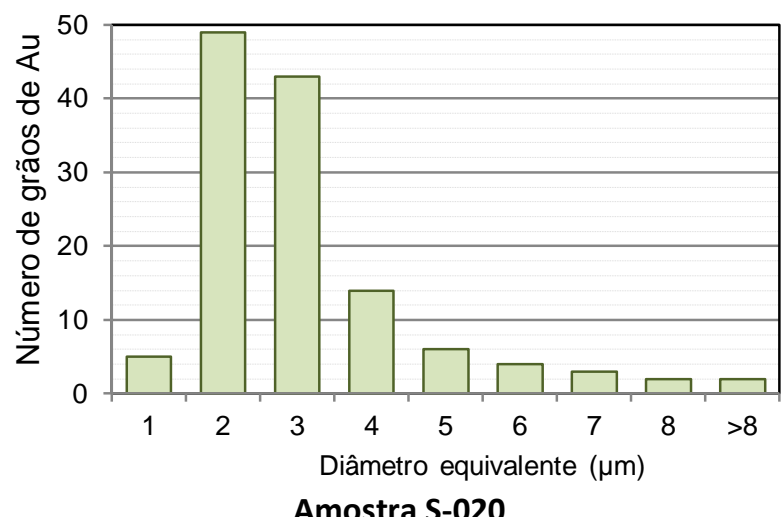

Amostra S-020

Figura 3 - Frequência de grãos de ouro por tamanho (diâmetro do círculo equivalente)

\subsection{Liberação do ouro e ocorrência em partículas livres ou mistas}

Através da análise de imagens no MLA, é possível determinar quantitativamente a fração em área de ouro exposto no perímetro das partículas portadoras ou a parcela totalmente inclusa nas mesmas. As informações a serem obtidas estão diretamente relacionadas com o processo a ser empregado; no caso em que o ouro ocorre associado a sulfetos e considerando-se uma etapa de concentração por flotação, é relevante determinar a proporção de ouro associado às diferentes fases sulfetadas e a porcentagem em que os sulfetos ocorrem com superfície exposta. Já para a cianetação, deve-se considerar tanto a proporção de ouro exposto como acessível por microfraturas, sendo esta última impossível de ser determinada por análise de imagens 2D.

As porcentagens em área dos grãos de ouro com perímetro exposto a partir de medidas 2D por MEV-MLA são apresentadas na Figura 4 e indicam que no produto afundado das frações acima de $0,037 \mathrm{~mm}, 63 \%$ em área do ouro da amostra B-020 encontra-se exposto e $47 \%$ para a amostra S-020.

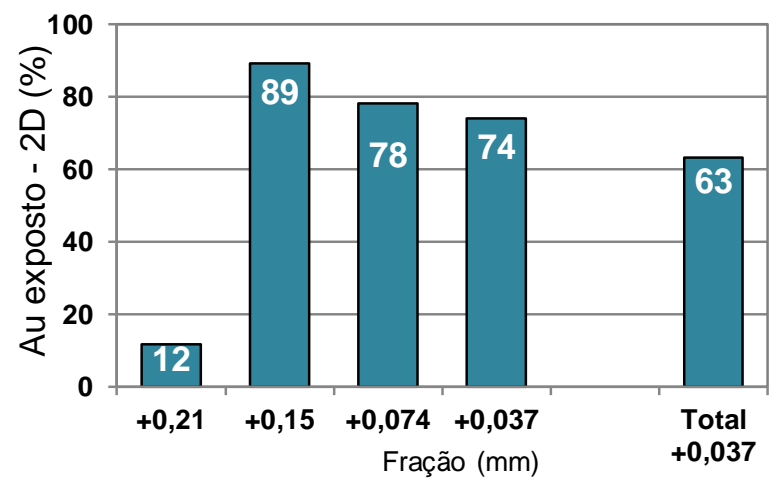

Amostra B-020

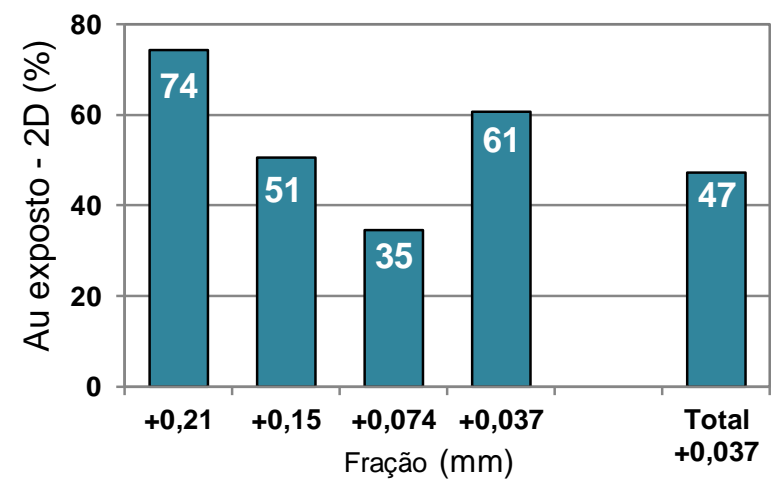

Amostra S-020 
Figura 4 - Fração em área do total de grãos de ouro com perímetro exposto no produto afundado para as amostras estudadas

\subsection{Extração do ouro por lixiviação por cianeto}

Os resultados da lixiviação por cianeto nos produtos da separação em líquido denso e nos finos abaixo de 0,037 mm são apresentados na Tabela 2, bem como as recuperações de ouro passíveis de serem obtidas na solução cianetada e a perdas remanescentes no resíduo sólido.

Tabela 2 - Distribuição de ouro nas amostras após etapa de lixiviação

\begin{tabular}{|c|c|c|c|c|c|c|c|}
\hline \multirow{2}{*}{$\begin{array}{l}\text { Fração (mm) / } \\
\text { Produto }\end{array}$} & \multirow{2}{*}{$\begin{array}{l}\text { Produto da } \\
\text { cianetação }\end{array}$} & \multicolumn{2}{|c|}{ Teores (ppm) } & \multicolumn{2}{|c|}{$\begin{array}{c}\text { Recuperação de Au } \\
\text { no ensaio (\%) }\end{array}$} & \multicolumn{2}{|c|}{$\begin{array}{c}\text { Recuperação de Au na } \\
\text { amostra (\%) }\end{array}$} \\
\hline & & B-020 & S-020 & B-020 & S-020 & B-020 & S-020 \\
\hline \multirow{3}{*}{$\begin{array}{l}\text { FLUTUADO } \\
\mathrm{d}<2,95 \mathrm{~g} / \mathrm{cm}^{3}\end{array}$} & Solução & 0,074 & 0,028 & 78,2 & 93,4 & 24,7 & 17,3 \\
\hline & Resíduo & 0,021 & 0,002 & 21,8 & 6,6 & 6,9 & 1,2 \\
\hline & Total calculado & 0,094 & 0,030 & 100,0 & 100,0 & 31,6 & 18,5 \\
\hline \multirow{3}{*}{$\begin{array}{l}\text { AFUNDADO } \\
\mathrm{d}<2,95 \mathrm{~g} / \mathrm{cm}^{3}\end{array}$} & Solução & 0,741 & 0,383 & 71,4 & 54,5 & 29,7 & 19,5 \\
\hline & Resíduo & 0,297 & 0,320 & 28,6 & 45,5 & 11,9 & 16,3 \\
\hline & Total calculado & 1,038 & 0,702 & 100,0 & 100,0 & 41,5 & 35,8 \\
\hline \multirow[t]{3}{*}{$-0,037 \mathrm{~mm}$} & Solução & 0,305 & 0,240 & 76,6 & 81,4 & 20,5 & 37,2 \\
\hline & Resíduo & 0,093 & 0,055 & 23,4 & 18,6 & 6,3 & 8,5 \\
\hline & Total calculado & 0,398 & 0,295 & 100,0 & 100,0 & 26,8 & 45,7 \\
\hline \multirow{3}{*}{$\begin{array}{l}\text { Total na amostra } \\
\left(P_{80}=0,21 \mathrm{~mm}\right)\end{array}$} & Solução & 0,085 & 0,045 & 75,0 & 73,9 & 75,0 & 73,9 \\
\hline & Resíduo & 0,028 & 0,016 & 25,0 & 26,1 & 25,0 & 26,1 \\
\hline & Total calculado & 0,226 & 0,122 & 100,0 & 100,0 & 100,0 & 100,0 \\
\hline
\end{tabular}

Do total de ouro contido na amostra, para a amostra B-020, verifica-se que $31,6 \%$ estão associados ao produto flutuado, $41,5 \%$ ao afundado e $26,8 \%$ encontra-se junto aos finos abaixo de $0,037 \mathrm{~mm}$. Para a amostra S- $020,18,5 \%$ do ouro contido encontram-se junto ao produto flutuado, $45,7 \%$ nos finos e apenas $35,8 \%$ no produto afundado.

$\mathrm{Na}$ amostra B-020, a recuperação do ouro por cianetação indica recuperações entre 71 a $79 \%$, nos ensaios, ou seja, entre 22 a $29 \%$ do ouro não é passível de ser recuperado por cianetação. Já na amostra S-020, as recuperações de ouro são bastante elevadas no produto flutuado $(93,4 \%)$ e nos finos $(81,4 \%)$, e medianas no produto afundado $(73,9 \%)$.

Comparando-se os resultados obtidos no ensaio de lixiviação por cianeto com a fração em área de grãos de ouro com perímetro exposto, pode-se observar que a recuperação no produto afundado foi de $71,4 \%$ e $54,5 \%$ para as amostras B-20 e S-20 respectivamente, enquanto que a fração de ouro exposto é $63 \%$ e $47 \%$ para as amostras B-20 e S-20.

As recuperações de ouro por cianetação são maiores do que a proporção de ouro exposto no perímetro das partículas (fração em área do total de grãos de ouro com perímetro exposto), pois os resultados de MLA referem-se a duas dimensões gerando dados de acessibilidade potencial inferiores à realidade tridimensional (valores mínimos de extração); adicionalmente, microfissuras nos minerais de ganga podem aumentar ainda mais a extração do ouro por cianetação. 


\section{CONCLUSÕES}

A identificação das diferenças de composição mineralógica e, principalmente, das associações do ouro são fundamentais para o direcionamento do processamento de minérios auríferos, sendo que a análise de imagens por feixe de elétrons permite essa quantificação com robustez estatística.

A conjugação de métodos de caracterização, visando à identificação das associações de ouro, bem como a determinação da proporção de ouro livre ou misto, incluso, exposto ou refratário, é fundamental para a estimativa das recuperações metalúrgicas, definição dos fluxogramas de processamento e ações para aumento de recuperação em operações industriais. Em projetos em curso, os estudos contribuem para o entendimento do comportamento do minério frente aos processos de beneficiamento empregados, possibilitando a identificação de possíveis perdas junto aos rejeitos e em processos ineficientes. Cabe ressaltar que as recuperações de ouro estimadas por análises 2D tendem a ser inferiores do que as alcançadas por cianetação em escala laboratorial; no entanto, as recuperações metalúrgicas em escala industrial deverão ser intermediárias a ambas.

\section{REFERÊNCIAS BIBLIOGRÁFICAS}

1. GOODALL, W. R., SCALES P. J., An overview of the advantages and disadvantages of the determination of gold mineralogy by automated mineralogy. In.: Minerals Engineering 20, p. 506-517 (2007).

2. GU, Y., Automated Scanning Electron Microscope Based Mineral Liberation Analysis. An Introduction to JKMRC/ FEI Mineral Liberation Analyser, In.: Journal of Minerals \& Materials Characterization \& Engineering, Vol. 2, No. 1, p. 33-41 (2003).

3. NEUMANN, R., SCHNEIDER, C. L., ALCOVER NETO, A., Caracterização Tecnológica de Minérios. In.: CT2002-136-00 Comunicação técnica elaborada para a 3a. edição do livro Tratamento de Minérios, Rio de Janeiro, 81 p. (2002).

4. SANT'AGOSTINO, L. M.; KAHN, H., Metodologia para Caracterização Tecnológica de Matérias Primas Mineral. In.: Tese (Boletim técnico) - Escola Politécnica, Universidade de São Paulo, São Paulo, 29 p. (1997). 